\title{
Invariance to frequency and time dilation along the ascending ferret auditory system
}

\author{
Alexander G Dimitrov ${ }^{1 *}$, Jean F Lienard ${ }^{1}$, Zachary Schwartz ${ }^{2}$, Stephen V David ${ }^{2}$ \\ From 24th Annual Computational Neuroscience Meeting: CNS*2015 \\ Prague, Czech Republic. 18-23 July 2015
}

The sense of hearing requires a balance between competing processes of perceiving and ignoring. Behavioral meaning depends on the combined values of some sound features but remains invariant to others. The invariance of perception to physical transformations of sound can be attributed in some cases to local, hardwired circuits in peripheral brain areas. However, at a higher level this process is dynamic and continuously adapting to new contexts throughout life. Thus the rules defining invariant features can change.

In this project, we test the idea that high-level, coherent auditory processing is achieved through hierarchical bottom-up combinations of neural elements that are only locally invariant. The main questions we address in the context of an auditory system are: 1 . What kinds of changes in sound do not affect initial stages of auditory processing? 2. How does the brain manipulate these small effects to achieve a coherent percept of sounds?

Local probabilistic invariances, defined by the distribution of transformations that can be applied to a sensory stimulus without affecting the corresponding neural response [1,2], are largely unstudied in auditory cortex. We assess these invariances at two stages of the auditory hierarchy using single neuron recordings from the primary auditory cortex (A1) and the secondary auditory cortex (PEG) of awake, passively listening ferrets [3,4].

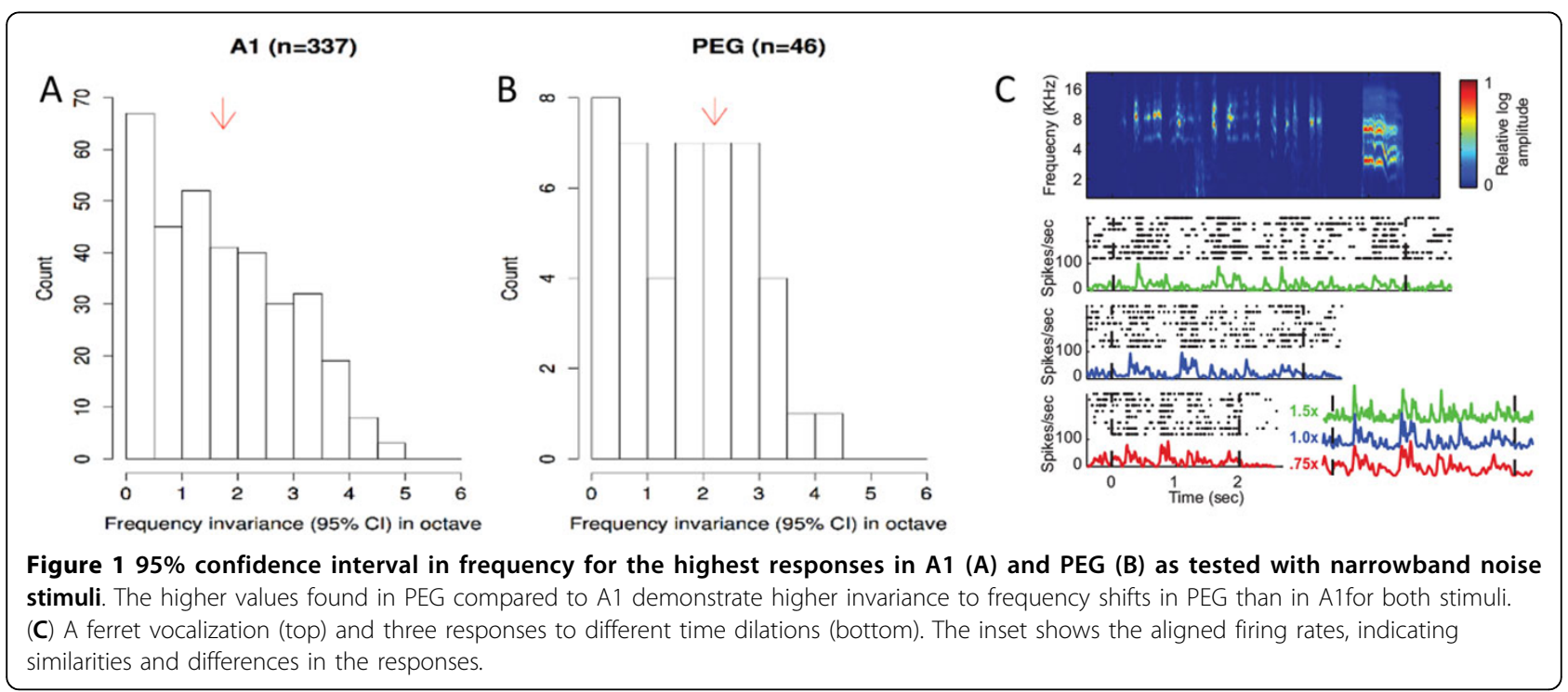

\footnotetext{
* Correspondence: alex.dimitrov@vancouver.wsu.edu

'Department of Mathematics, Washington State University Vancouver,

Vancouver, WA 98686, USA

Full list of author information is available at the end of the article
} 
Our results show that stimulus invariance to frequency and time dilations are present at every tested stage and increase along the hierarchical auditory processing. At least in the early stages, parametric models having invariance properties by design are well-suited to describing biological functions. We were further able to characterize meaningful relationships among receptive field shapes. Preliminary observations indicate that joint time/frequency receptive fields are oriented toward central frequencies; receptive field widths are proportional to the best frequency; and late-onset neurons are also exhibiting the most sustained activity.

\section{Authors' details}

'Department of Mathematics, Washington State University Vancouver,

Vancouver, WA 98686, USA. ${ }^{2}$ Department of Otolaryngology, Oregon Health

Sciences University, Portland, OR 97239, USA.

Published: 18 December 2015

\section{References}

1. Aldworth ZN, Miller JP, Gedeon T, Cummins Gl, Dimitrov AG: Dejittered spike-conditioned stimulus waveforms yield improved estimates of neuronal feature sensitivity. J Neuro 2005, 25(22):5323-5332.

2. Dimitrov $A G$, Gedeon $T$ : Effects of stimulus transformations on the perceived function of sensory neurons. J Comp Neuro 2006, 20:265-283.

3. Atiani S, David SV, Elqueda D, Locastro M, Radtke-Schuller S, Shamma SA, Fritz JB: Emergent selectivity for task-relevant stimuli in higher order auditory cortex. Neuron 2014, 82(2):486-99.

4. David SV, Mesgarani N, Shamma SA: Estimating sparse spectro-temporal receptive fields with natural stimuli. Network 2007, 18(3):191-212.

doi:10.1186/1471-2202-16-S1-P51

Cite this article as: Dimitrov et al.: Invariance to frequency and time dilation along the ascending ferret auditory system. BMC Neuroscience 2015 16(Suppl 1):P51.

\section{Submit your next manuscript to BioMed Central} and take full advantage of:

- Convenient online submission

- Thorough peer review

- No space constraints or color figure charges

- Immediate publication on acceptance

- Inclusion in PubMed, CAS, Scopus and Google Scholar

- Research which is freely available for redistribution

Submit your manuscript at www.biomedcentral.com/submit
C Biomed Central 